\title{
Effects of Isothermal Aging on Microstructure and Mechanical Property of Low-Carbon RAFM Steel
}

\author{
Jian-Guo Chen ${ }^{1,2} \cdot$ Chen-Xi Liu ${ }^{1}$ Chen $\mathrm{Wei}^{2} \cdot$ Yong-Chang Liu ${ }^{1} \cdot$ Hui-Jun Li ${ }^{1}$
}

Received: 13 October 2018 / Revised: 6 November 2018 / Published online: 21 February 2019

(c) The Chinese Society for Metals (CSM) and Springer-Verlag GmbH Germany, part of Springer Nature 2019

\begin{abstract}
In order to investigate the microstructure and mechanical property evolution of low-carbon reduced activation ferritic/ martensitic (RAFM) steel during isothermal aging, the normalized and tempered specimens were aged at $600{ }^{\circ} \mathrm{C}$ for 500 , 1000 , and $3000 \mathrm{~h}$, respectively. The microstructural evolution with aging time was analyzed, including the precipitation and growth of $M_{23} \mathrm{C}_{6}$ and $M X$-type carbides as well as the formation of Laves phase. The results indicate that the coarsening of $M_{23} \mathrm{C}_{6}$ is more obvious than that of $M X$ with increase in aging time. During the long-term thermal exposure, the $\mathrm{Fe}_{2} \mathrm{~W}$ Laves phase precipitates adjacent to $M_{23} \mathrm{C}_{6}$ along the prior austenite grain boundaries and packet boundaries. Lower carbon content can delay the precipitation of Laves phase compared to the steel containing higher carbon. In addition, the Laves phase precipitated along boundaries can provide the precipitation strengthening, slightly increasing the tensile strength of low-carbon RAFM steel after aging for $3000 \mathrm{~h}$.
\end{abstract}

Keywords Low-carbon RAFM steel $\cdot$ Isothermal aging $\cdot$ Microstructure evolution $\cdot$ Mechanical property

\section{Introduction}

Structural materials with excellent performance would be critical for the successful operation of future fusion energy reactors. Reduced activation ferritic-martensitic (RAFM) steels have been regarded as the preferential candidate structural material in the fusion reactors owing to better thermophysical properties, optimum application temperature, and better low activation in high-dose fusion reactor environment [1-3]. The RAFM steels were produced by composition modification of the traditional $\mathrm{Cr}-\mathrm{Mo}$ heat-resistant steel. In order to reduce activation, the long-lived transmutation elements such as $\mathrm{Mo}, \mathrm{Nb}$, and $\mathrm{Co}$ are usually replaced

Available online at http://link.springer.com/journal/40195

Chen-Xi Liu

cxliutju@163.com

Yong-Chang Liu

licmtju@163.com

1 State Key Lab of Hydraulic Engineering Simulation and Safety, School of Materials Science and Engineering, Tianjin University, Tianjin 300350, China

2 Tianjin Special Equipment Inspection Institute, Tianjin 300192, China by relatively short-lived transmutation elements Ta and W. A lot of research and development activities on RAFM steels were conducted in many countries in the past decades. Chen et al. [4-6] studied the hot deformation behavior, microstructure, and mechanical properties of RAFM steel, as well as its austenitic transformation kinetics. Xia et al. [7, 8] investigated the effects of intermediate heat treatment on precipitation behavior and creep property of RAFM steel. Klueh et al. [9] and Huang et al. [10] studied the microstructure and mechanical properties of $9 \mathrm{Cr}-2 \mathrm{~W}$ steel and CLAM steel. Mao et al. [11] reported the tensile deformation behavior of RAFM steel. Zhang et al. [12] investigated the friction stir welding of RAFM steel. Liu et al. [13, 14] attained nanocrystallization of RAFM steel and improved creep resistance by nitrogen addition.

The first wall components of nuclear reactors have been conceptually designed to serve in the application temperatures of $250-550{ }^{\circ} \mathrm{C}$ for RAFM steel [15]. In the fusion reactors, the increase in service temperature is crucial to improving the utilization of nuclear energy, and structural material in service should meet the requirement for more high-temperature resistance accordingly. The improvement in high-temperature mechanical properties relies heavily on the composition, original microstructure of steels, and its long-term stability at high temperatures [16]. For 9Cr ferritic-martensitic steel, carbon 
content has an important influence on its microstructure and mechanical properties. Krauss [17] reported that the strength of quenched martensite microstructure was improved by increasing carbon content. Morito et al. [18] found that the density of dislocation within martensitic lath and the number of the retained austenite have a close relationship with the carbon content. As important carbide forming element, carbon content is vital to control the precipitation behavior and high-temperature mechanical properties of steels. The creep property of 9\% Cr martensitic steel is improved by decreasing the carbon content from $0.047 \%$ to $0.018 \%$ and $0.002 \%$ [19]. Dense $M X$ carbonitrides on grain boundaries in the steel with $0.002 \%$ carbon content effectively improve the strengthening effect of $M X$ carbonitride precipitation [20]. Therefore, decrease in carbon content in $9 \% \mathrm{Cr}$ martensitic steel is an effective way to improve the high-temperature performance. However, under low-carbon condition, the comprehensive study of RAFM steel during high-temperature service is limited. Aimed at improving the operating temperature of RAFM steel, the carbon content of RAFM steel in this work was decreased, and the aging tests of specimens at $600{ }^{\circ} \mathrm{C}$ were conducted. Microstructural evolution and the homologous mechanical properties changes of low-carbon RAFM steels during long-term thermal aging at high temperatures were investigated. The main objective of the present work is to investigate the effects of aging time on the microstructural evolution of the low-carbon RAFM steel during aging to clarify the mechanical property changes caused by microstructure variation.

\section{Materials and Experimental Methods}

The designed low-carbon RAFM steel was melted into an ingot weight $25 \mathrm{~kg}$, followed by hot-rolling into cylinder bars with a size of $120 \mathrm{~mm}$ in height and $60 \mathrm{~mm}$ in diameter. The detailed chemical compositions of the steel are given in Table 1 . The heat treatment processes of low-carbon RAFM steels before aging test included two steps: firstly austenitizing at $1050{ }^{\circ} \mathrm{C}$ for $0.5 \mathrm{~h}$ followed by air cooling to room temperature, and then a tempering at $750{ }^{\circ} \mathrm{C}$ for $1.5 \mathrm{~h}$. Isothermal aging tests of low-carbon RAFM steels were conducted at temperature of $600{ }^{\circ} \mathrm{C}$ for 500,1000 , and $3000 \mathrm{~h}$, respectively. The cylindrical tensile specimens with a diameter of $5 \mathrm{~mm}$ and a gauge length of $25 \mathrm{~mm}$ were produced at room temperature and $600{ }^{\circ} \mathrm{C}$. Two samples were used in each tensile condition for specimens after normalizing and tempering ( $\mathrm{N}$ and $\mathrm{T}$ ) heat treatments and thermal aging.

The microstructure of steel after aging was observed by optical microscopy and scanning electron microscopy. The precipitation and coarsening behavior of precipitate phases were analyzed through the transmission electron microscopy, and the identification of the precipitate type was carried out by using electron diffraction pattern analysis. The samples for TEM were mechanically polished, followed by twin-jet polishing with a solution of $5 \mathrm{vol} \%$ perchloric acid in ethanol. The morphology, size, and distribution of $M X$ phase particles were observed by the carbon extraction replica technique. After deep etching and carbon coating, the specimen surface was lightly scored into squares of $2.5 \mathrm{~mm}$ side length, and then bulk replicas were liberated in the mixed solution of hydrochloric acid and copper chloride, followed by making the replicas float in ethanol and water. Copper TEM grids were used to dry up the replicas.

\section{Results and Discussion}

\subsection{Microstructures}

Figure 1 shows the microstructure characteristics of the specimens after $\mathrm{N}$ and $\mathrm{T}$ heat treatment, exhibiting the typical tempered martensitic microstructure, and several packets are formed in each prior austenite grain, as shown in the OM micrograph of Fig. 1a. The grain size of specimen is measured as about $18 \mu \mathrm{m}$. Figure $1 \mathrm{~b}$ shows the TEM micrograph of the specimen. The width of tempered martensitic laths is in the range of $0.2-0.7 \mu \mathrm{m}$, and some precipitates were found to distribute along the martensitic lath boundaries. The linear intercept method was used to measure the grain size and martensitic laths width.

The SEM micrographs of specimens after $\mathrm{N}$ and $\mathrm{T}$ and thermal aging at $600{ }^{\circ} \mathrm{C}$ for 500,1000 , and $3000 \mathrm{~h}$ are shown in Fig. 2. It can be found that the change in grain size of steels after $\mathrm{N}$ and $\mathrm{T}$ and thermal aging for different times is small, which indicates that the migration of the grain boundaries is not evident during aging. This can be explained by the fact that this low temperature does not provide sufficient surface energy for the mobility of the grain boundaries.

Figure 3 presents the variation of precipitates by SEM. According to the previous work, the primary precipitate was Cr-rich $M_{23} \mathrm{C}_{6}$-type carbides along grain boundaries [21]. However, for the specimen after $3000 \mathrm{~h}$ aging, the precipitates with larger size were decorated along grain boundaries, as shown in Fig. 3d. Figure 3f shows the energy-dispersive spectrometer (EDS) analysis of the area squared in Fig. 3d, indicating that the main elements in the precipitate are $\mathrm{W}$ and Fe.
Table 1 Chemical composition of the low-carbon RAFM steel (wt \%)

\begin{tabular}{lllllllll}
\hline $\mathrm{C}$ & $\mathrm{N}$ & $\mathrm{Cr}$ & $\mathrm{W}$ & $\mathrm{Mn}$ & $\mathrm{Si}$ & $\mathrm{V}$ & $\mathrm{Ta}$ & $\mathrm{Fe}$ \\
\hline 0.04 & 0.02 & 8.93 & 1.71 & 0.44 & 0.04 & 0.22 & 0.073 & Bal. \\
\hline
\end{tabular}



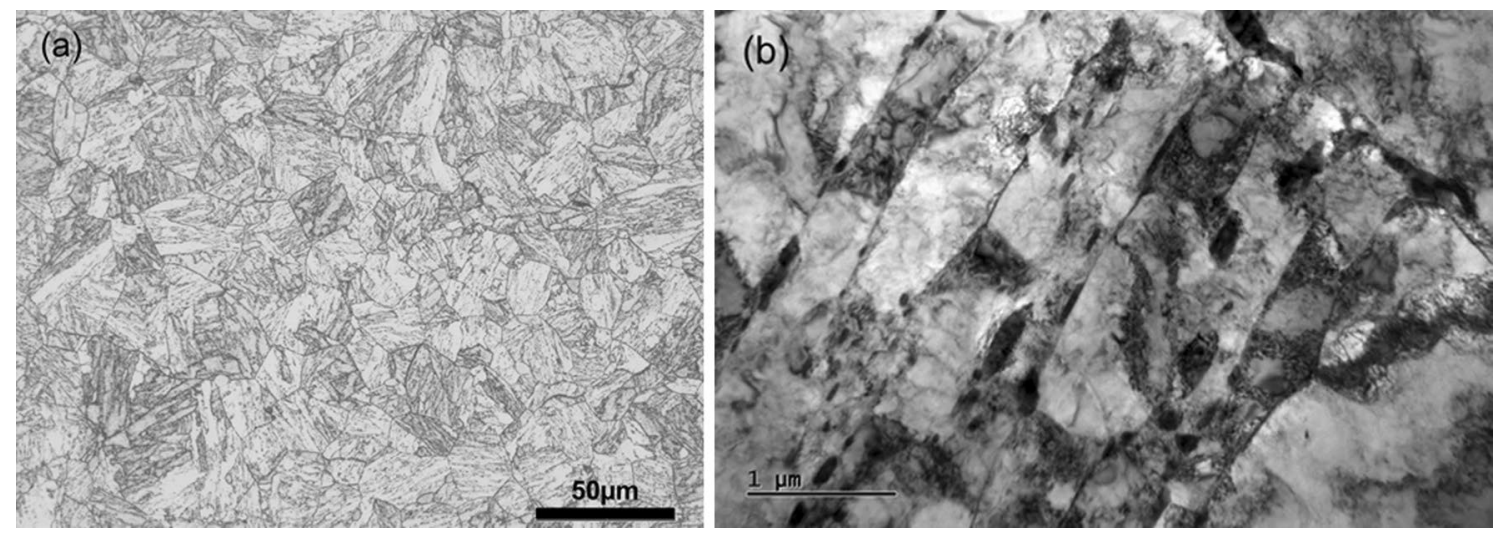

Fig. 1 Micrographs of low-carbon RAFM steel after N and T heat treatment: a OM, b TEM
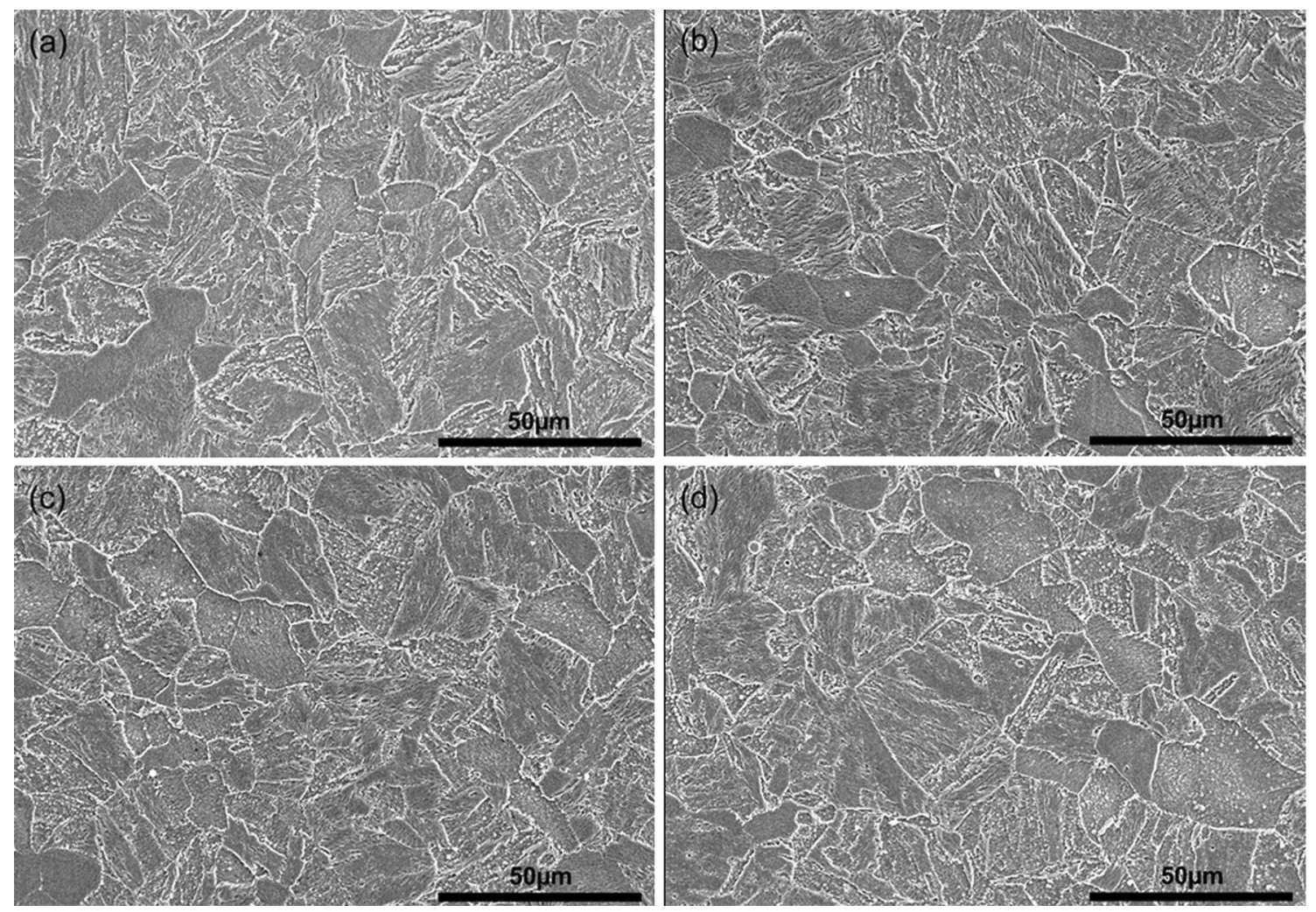

Fig. 2 Low-magnification SEM images of low-carbon RAFM steel: a N and T heat treatment, $\mathbf{b}$ aging for $500 \mathrm{~h}, \mathbf{c}$ aging for $1000 \mathrm{~h}, \mathbf{d}$ aging for $3000 \mathrm{~h}$

Figure 4 shows the evolution of carbides and martensitic lath in detail. A lath structure decorated by $\mathrm{Cr}$-rich $M_{23} \mathrm{C}_{6}$ type carbides can be found in $\mathrm{N}$ and $\mathrm{T}$ specimens, as shown in Fig. 4a. The microstructure of specimens for $\mathrm{N}$ and $\mathrm{T}$ and thermal aging all presents martensitic microstructure, and the average width of lath is slightly increased from about $0.45 \mu \mathrm{m}$ in $\mathrm{N}$ and $\mathrm{T}$ state to 0.52 and $0.58 \mu \mathrm{m}$ after aging for 1000 and $3000 \mathrm{~h}$, respectively. This can be explained by the fact that the high-temperature tempering treatment of low-carbon RAFM steel at $750{ }^{\circ} \mathrm{C}$ is beneficial to achieving a relatively stable microstructure, and the subsequent aging treatment at $600{ }^{\circ} \mathrm{C}$ is too low to change the microstructural features. Moreover, the dislocation movement is weak at a lower temperature, and the dislocation substructure is pinned by the $M X$-type precipitation. The larger precipitate along boundaries after aging for $3000 \mathrm{~h}$ was confirmed as $\mathrm{Fe}_{2} \mathrm{~W}$ Laves phase with a hexagonal structure through electron diffraction patterns analysis, as presented in Fig. 4f. Xia et al. 

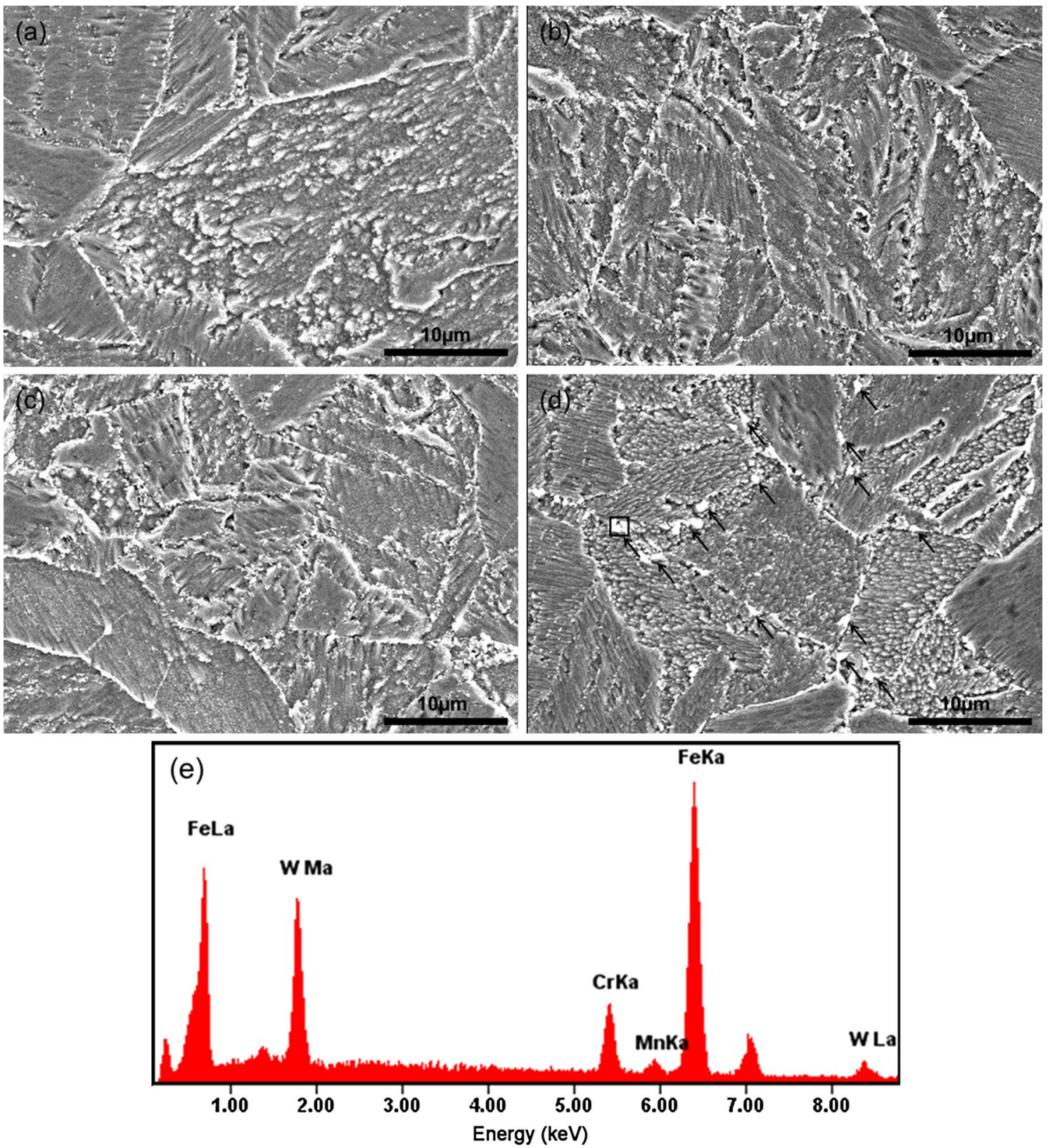

Fig. 3 High-magnification SEM images of low-carbon RAFM steel: a N and T heat treatment, $\mathbf{b}$ aging for $500 \mathrm{~h}, \mathbf{c}$ aging for $1000 \mathrm{~h}, \mathbf{d}$ aging for $3000 \mathrm{~h}$, e energy-dispersive spectrometer of the area indicated by square in $\mathbf{d}$

[22] found that the $\mathrm{Fe}_{2} \mathrm{Mo}$ Laves phase precipitates along martensite lath and packet boundaries in P91 steel at $576{ }^{\circ} \mathrm{C}$ for $5800 \mathrm{~h}$.

The previous work reported that Cr-rich $M_{23} \mathrm{C}_{6-}$ type carbides and $M X$-type carbonitrides were main precipitates in ferritic/martensitic steel during $\mathrm{N}$ and $\mathrm{T}$ heat treatment, and the $M_{23} \mathrm{C}_{6}$-type carbides precipitated along the grain boundaries and lath boundaries, while $M X$-type carbonitrides were distributed in martensite lath $[5,23,24]$. Figure 5 gives micrographs of carbon extraction replica showing the distribution of precipitates along boundaries. With an increase in the aging time, the number and size of $M_{23} \mathrm{C}_{6-}$ type carbides are increased, as shown in Fig. $5 \mathrm{~b}$ and d, and no evidence of Laves phase is found in low-carbon RAFM steel after aging for 500 and $1000 \mathrm{~h}$. The large-sized Laves phase precipitates are present along the boundaries when the aging time reaches 3000 h, as shown in Fig. 5d. Figure 5e and f reveals the electron diffraction patterns of Cr-rich $M_{23} \mathrm{C}_{6-}$ type carbide and $\mathrm{Fe}_{2} \mathrm{~W}$ Laves phase.

Figure 6 shows the TEM images of $M X$-type precipitate in the $\mathrm{N}$ and $\mathrm{T}$ and aged samples. It can be found that the size of $M X$-type precipitate changes little after aging, and the 

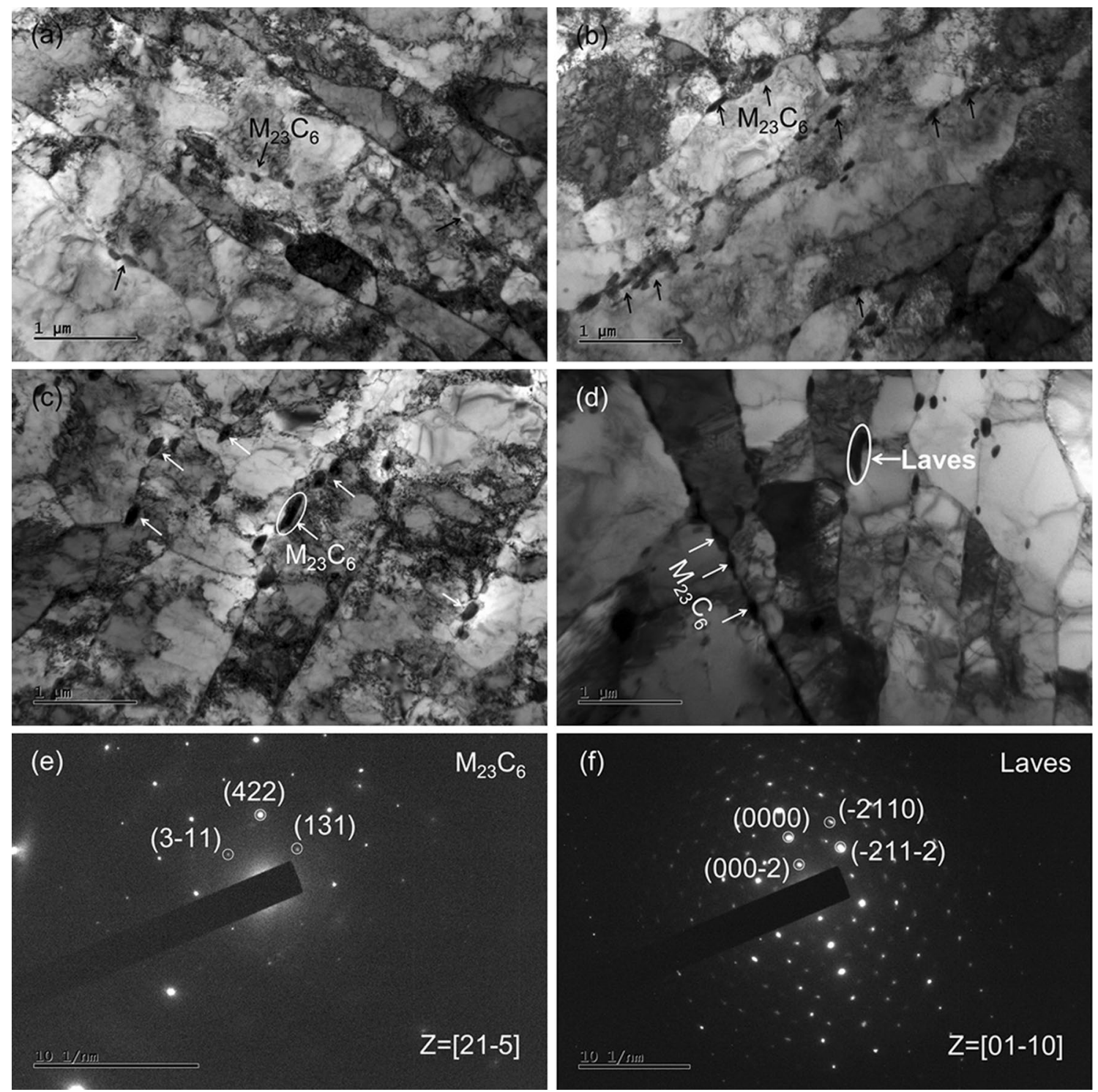

Fig. 4 TEM images of low-carbon RAFM steel microstructure: a $\mathrm{N}$ and $\mathrm{T}$ heat treatment, $\mathbf{b}$ aging for $500 \mathrm{~h}$, $\mathbf{c}$ aging for $1000 \mathrm{~h}$, $\mathbf{d}$ aging for $3000 \mathrm{~h}, \mathbf{e}, \mathbf{f}$ electron diffraction pattern of $M_{23} \mathrm{C}_{6}$ and Laves phase

fine $M X$ can be observed clearly even after thermal aging for $3000 \mathrm{~h}$. This demonstrates the $M X$-type carbonitrides have lower coarsening rate compared with $M_{23} \mathrm{C}_{6}$-type carbide. For RAFM steels, $M X$-type carbonitrides mainly precipitate around the dislocations in the matrix, which provides the pinning effect on dislocations and improves the hightemperature mechanical properties. Zhou et al. studied the precipitation behavior of type $347 \mathrm{H}$ heat-resistant austenitic steel during aging, finding that $M X$-type carbonitrides were the predominant strengthening precipitates [25]. Chen et al. found that the $M X$-type carbonitrides can improve the creep property of RAFM steel [26]. The electron diffraction pattern of $M X$-type carbonitrides in Fig. 6e has been identified as $\mathrm{TaC}$ precipitate.
The size distribution of precipitates before and after isothermal aging is shown in Fig. 7. The average size of Cr-rich $M_{23} \mathrm{C}_{6}$-type carbide is $95 \mathrm{~nm}$ in the initial $\mathrm{N}$ and $\mathrm{T}$ state and then reaches $120 \mathrm{~nm}$ after aging at $600{ }^{\circ} \mathrm{C}$ for $1000 \mathrm{~h}$ and continues to grow up to $143 \mathrm{~nm}$ after $3000 \mathrm{~h}$. The higher coarsening rate of $M_{23} \mathrm{C}_{6}$-type carbides is due to the much faster carbon atoms diffusion at grain boundaries and martensitic lath boundaries, which facilitates the nucleation and coarsening of $M_{23} \mathrm{C}_{6}$-type carbides [27]. However, the average size of $M X$-type carbonitrides slightly increases from 30 to $39 \mathrm{~nm}$ at $\mathrm{N}$ and $\mathrm{T}$ state and aging for $3000 \mathrm{~h}$, which indicates the high thermal stability of $M X$. Xia et al. [28] reported that the coarsening rate of $\mathrm{TaC}$ precipitates was low, since Ta has a large lattice misfit and a small solubility 

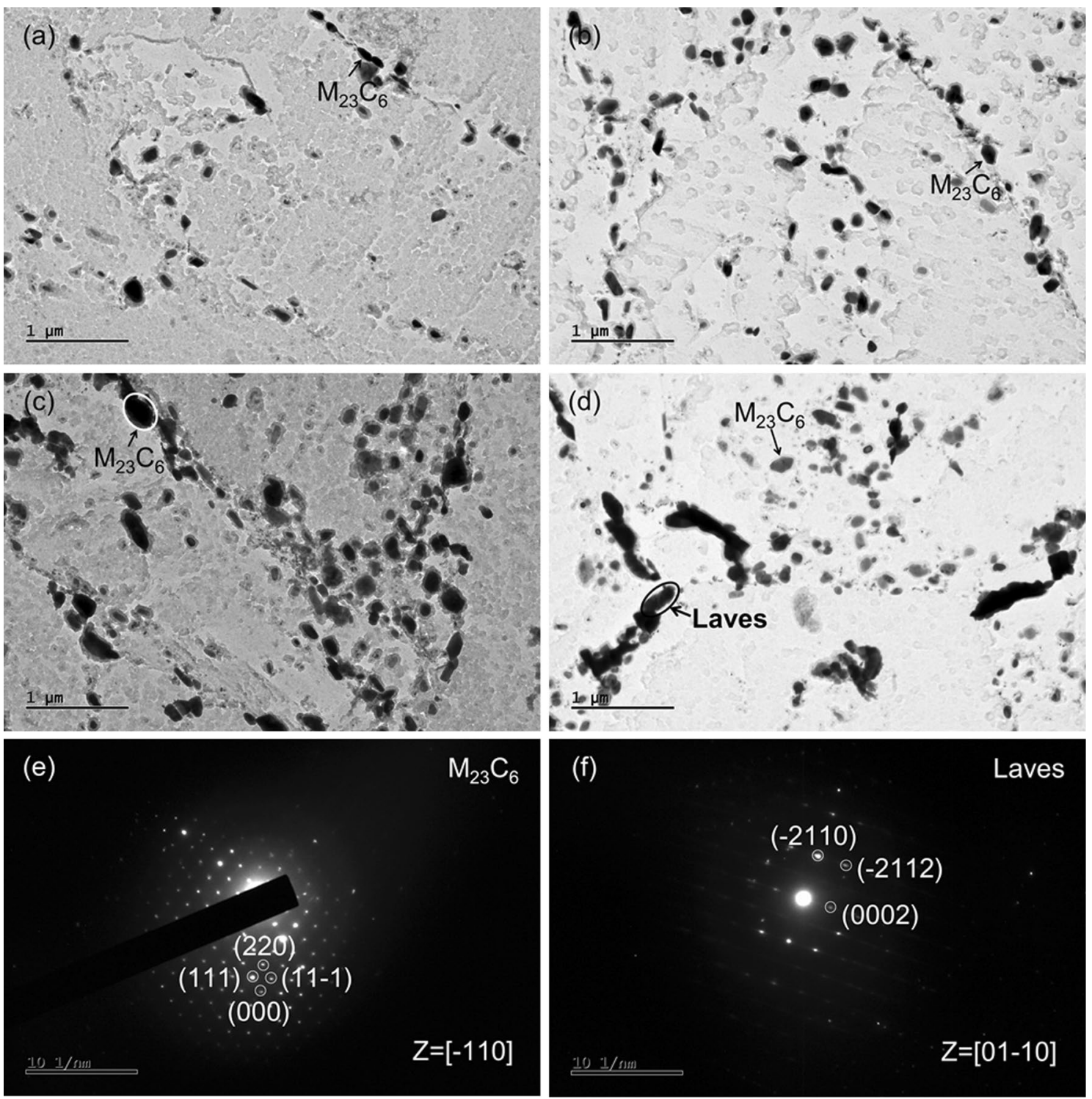

Fig. 5 TEM micrograph of carbon extraction replica for low-carbon RAFM steel: a distribution of $M_{23} \mathrm{C}_{6}$ after $\mathrm{N}$ and $\mathrm{T}$ heat treatment, $\mathbf{b}$ distribution of $M_{23} \mathrm{C}_{6}$ after aging for $500 \mathrm{~h}$, c distribution of $M_{23} \mathrm{C}_{6}$

in the ferrite matrix. The dispersed distribution of stable $M X$-type particle could act as obstacles of dislocation movement and annihilation, providing the pinning effect on dislocations and hindering effectively the dislocation motion [29].

\subsection{Laves Phase}

Laves phase is not found in the $\mathrm{N}$ and $\mathrm{T}$ state of low-carbon RAFM steel, since the formation of Laves phase requires the segregation and enrichment of $\mathrm{W}$ on the grain and lath boundaries. Therefore, it is generally formed under longtime thermal exposure. Klueh [30] reported that W concentration plays a dominant role in the formation of Laves

after aging for $1000 \mathrm{~h}, \mathbf{d}$ distribution of $M_{23} \mathrm{C}_{6}$ and Laves phase after aging for $3000 \mathrm{~h}, \mathbf{e}, \mathbf{f}$ electron diffraction pattern of $M_{23} \mathrm{C}_{6}$ and Laves phase

phase, the amount of Laves phase in 9Cr-2WVTa steel is $1.85 \%$, while there is only $0.23 \%$ Laves phase in $9 \mathrm{Cr}-$ $1 \mathrm{WVTa}$ steel. For nucleation of Laves phase, Cui et al. [31] reported two mechanisms: One is that Laves phase particles nucleation is in $\mathrm{Cr}$-depleted regions adjacent to $M_{23} \mathrm{C}_{6}$-type carbides; the other one is that the nucleation of Laves phase appears independently on grain boundaries without $M_{23} \mathrm{C}_{6}$-type carbides in the vicinity. In this study, it is noted that the $\mathrm{Fe}_{2} \mathrm{~W}$ Laves phase nucleates close to $M_{23} \mathrm{C}_{6}$-type carbides along grain boundaries and exhibits characteristic stacking fault, which can be easily distinguished from $M_{23} \mathrm{C}_{6}$-type precipitates present in the microstructure, as shown in Fig. 8a, b. Such regions 

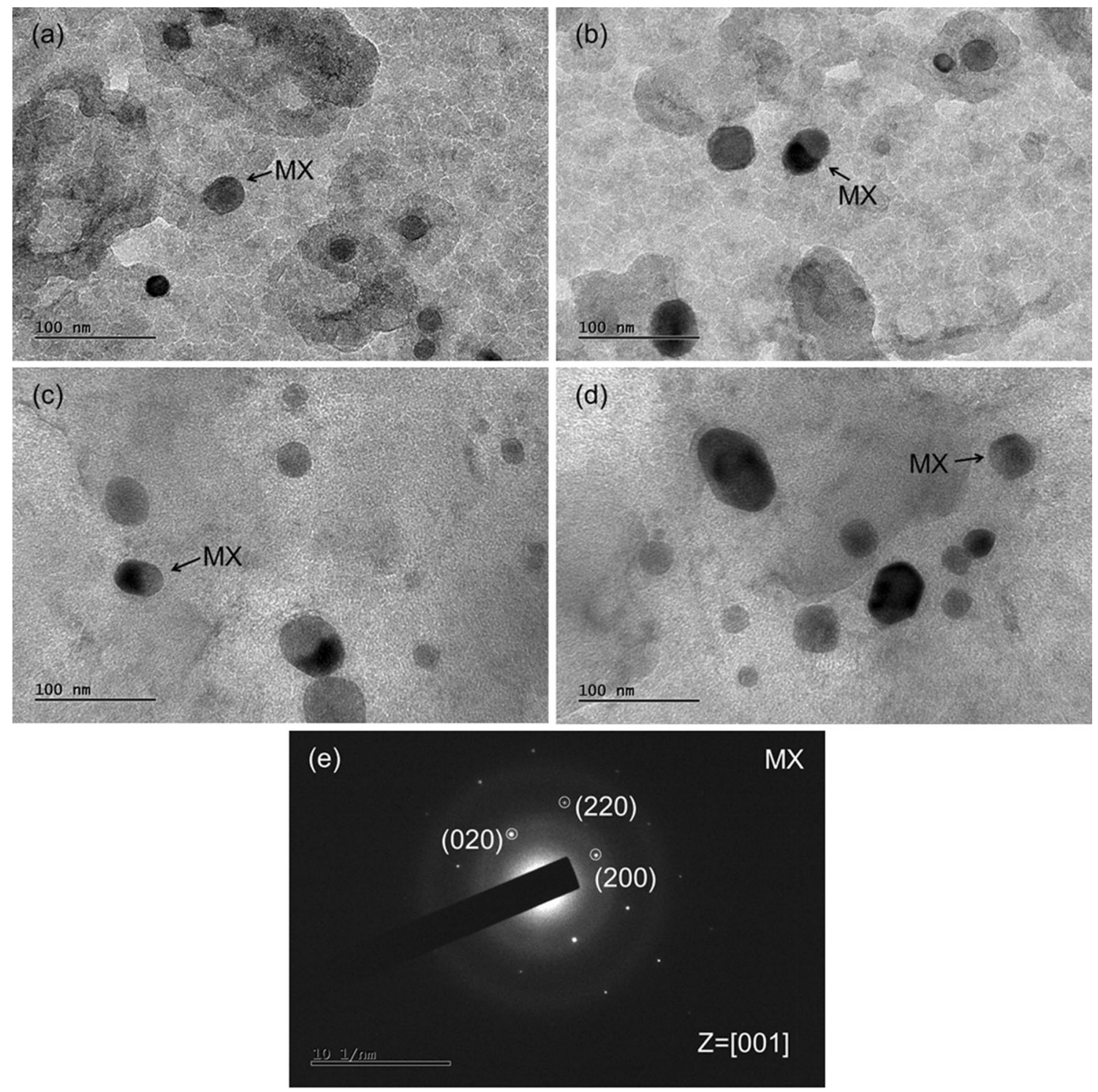

Fig. 6 TEM micrograph of carbon extraction replica for low-carbon RAFM steel showing distribution of MX phase after: $\mathbf{a} \mathrm{N}$ and $\mathrm{T}$ heat treatment, b aging for $500 \mathrm{~h}, \mathbf{c}$ aging for $1000 \mathrm{~h}, \mathbf{d}$ aging for $3000 \mathrm{~h}$, e electron diffraction pattern of $M X$

have high interfacial free energy, and the depletion of $\mathrm{Cr}$ caused by $M_{23} \mathrm{C}_{6}$ growth will lead to the W segregation at grain boundaries. Thus, the increase in amount of $\mathrm{W}$ will promote the forming of $\mathrm{Fe}_{2} \mathrm{~W}$ Laves phase. Xia et al. [22] reported the similar formation mechanism of $\mathrm{Fe}_{2} \mathrm{Mo}$ Laves phase in P91 steel. Guo et al. [32] found that the transformation from $\mathrm{NbC}$ into G-phase would release a large amount of carbon and created a relatively high concentration of carbon at grain boundaries, resulting in the formation of $M_{23} \mathrm{C}_{6}$ in $20 \mathrm{Cr} 32 \mathrm{Ni} 1 \mathrm{Nb}$ stainless steel. Wang et al. [33] reported that the formation of $(\mathrm{Ti}, \mathrm{Mo}) \mathrm{C}$ would lead to the decrease in carbon concentration in regions adjacent to (Ti, Mo)C, which would be favorable to the $\sigma$-phase formation. The diffraction patterns of $\mathrm{Fe}_{2} \mathrm{~W}$ Laves phase and $M_{23} \mathrm{C}_{6}$-type carbide are shown in Fig. 8c, d. In addition, the $\mathrm{Fe}_{2} \mathrm{~W}$ Laves phase precipitation of specimen in this work occurred until $3000 \mathrm{~h}$, which was longer than the $1100 \mathrm{~h}$ for CLAM steel [34]. An explanation for this circumstance may be related to the difference in carbon content between the two steels. The amount of $M_{23} \mathrm{C}_{6}$-type carbides would decrease owing to the decrease in carbon content [35]. At the same thermal exposure time, the lower volume fraction of $M_{23} \mathrm{C}_{6}$-type carbides is difficult to form the Cr-depleted regions (relatively high concentration of $\mathrm{W}$ in this region), which reduces the nucleation sites for $\mathrm{Fe}_{2} \mathrm{~W}$ Laves phase and retards the $\mathrm{Fe}_{2} \mathrm{~W}$ Laves phase precipitation. 


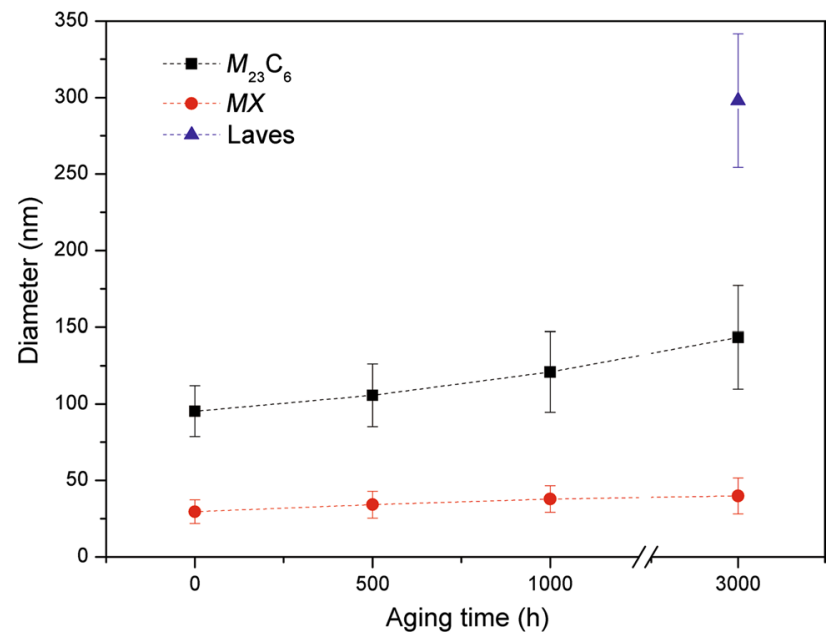

Fig. 7 Average sizes variation of precipitates in low-carbon RAFM steel before and after isothermal aging tests

\subsection{Mechanical Properties}

Figure 9 shows the tensile and yield strength of the lowcarbon RAFM steels at room temperature and $600{ }^{\circ} \mathrm{C}$ before and after different aging time. It can be found that the tensile strength and yield strength at different temperatures present the similar variation trend. Compared with $\mathrm{N}$ and $\mathrm{T}$ specimens, the strength of specimens increases after aging for $500 \mathrm{~h}$ and then decreases after aging for $1000 \mathrm{~h}$, finally increases after aging for $3000 \mathrm{~h}$. It is well acknowledged that the dislocations and precipitates have main strengthening effect on the mechanical properties of RAFM steels. Dislocation movement at higher temperature would lead to the production of dislocations walls, which could form the subgrain boundary. However, the dislocations strengthening could be neglected in this work, which can be explained by the following reasons: Firstly, the tempered martensitic microstructure of specimens is relatively stable for aging different time at $600{ }^{\circ} \mathrm{C}$. Even after aging $3000 \mathrm{~h}$, equiaxed subgrains could almost not be observed in the steel matrix, as shown in Fig. 4d, which indicated that the mobility of dislocations is relatively weak. Secondly, the stable $M X$ type carbonitrides precipitating inside martensite laths could provide the pinning effect on dislocations, which can effectively prevent the movement of dislocation during thermal aging. Therefore, the effect of evolution of martensite lath and dislocation structure on strength can be neglected, and the precipitates strengthening should be used to discuss the variation of tensile properties dominantly.

Generally, precipitation behavior in the steel consists of two stages. The first stage is the continuous nucleation of the precipitates, and the second stage is the growth and coarsening of precipitates. In the initial thermal aging stage,
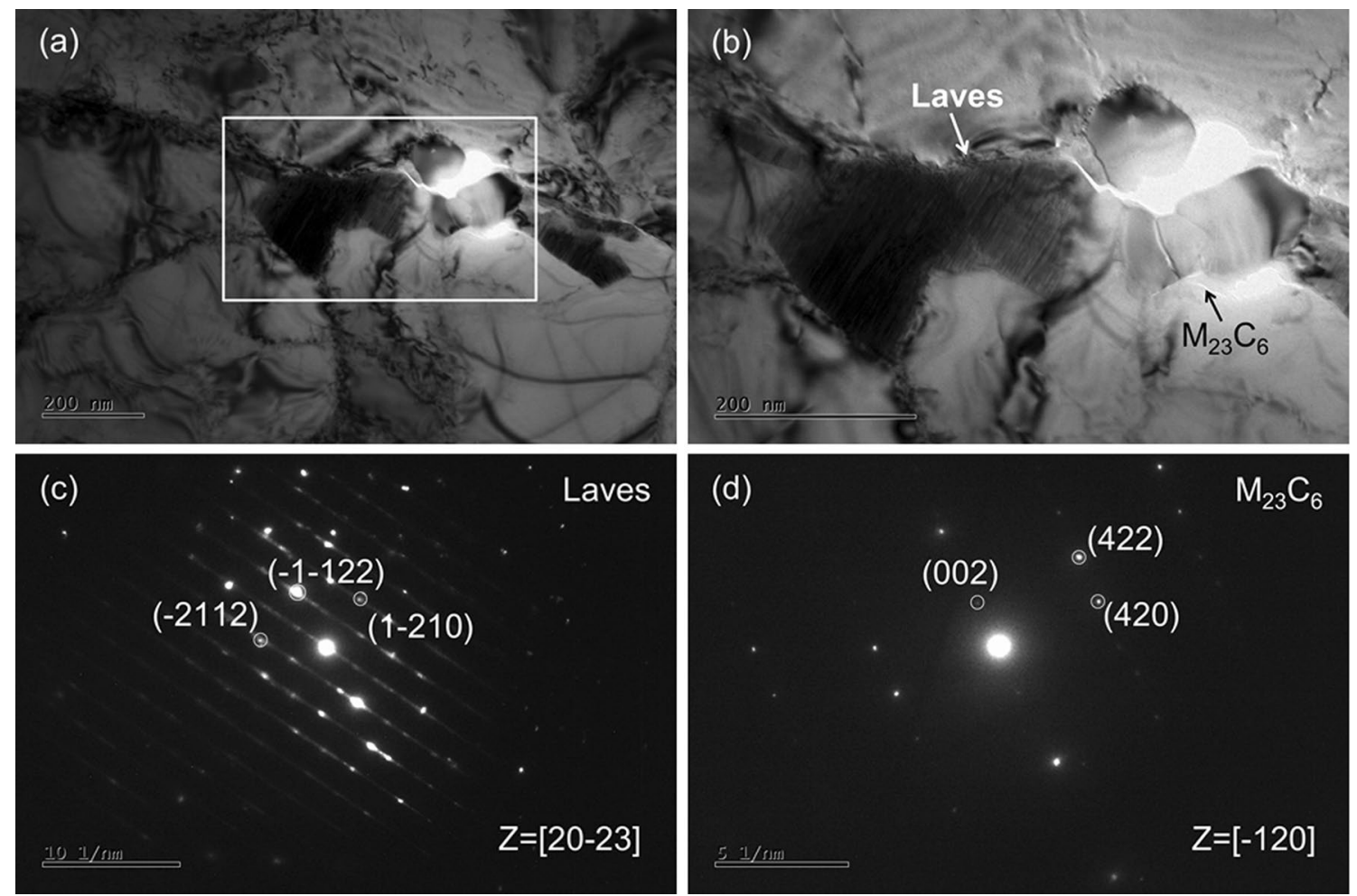

Fig. 8 TEM images of low-carbon RAFM steel: a the precipitation of Laves phase close to $M_{23} \mathrm{C}_{6}$ along grain boundaries, $\mathbf{b}$ enlarged view of the area indicated by square in $\mathbf{a}, \mathbf{c}$ and $\mathbf{d}$ electron diffraction pattern of Laves phase and $M_{23} \mathrm{C}_{6}$ 


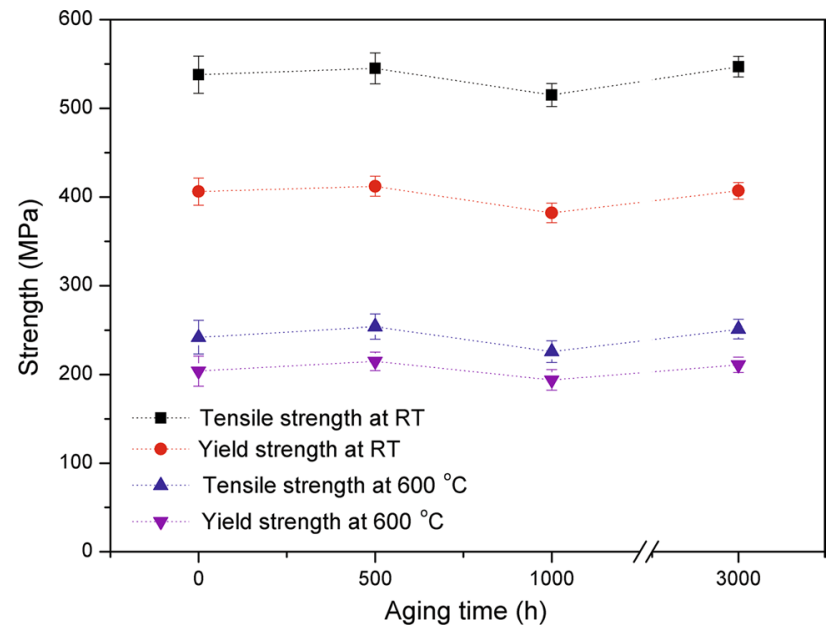

Fig. 9 Comparison of the tensile and yield strength of low-carbon RAFM steel at $\mathrm{N}$ and $\mathrm{T}$ state and thermal aging for 500, 1000 and $3000 \mathrm{~h}$

it is mainly characterized by the increase in the number of $M_{23} \mathrm{C}_{6}$-type carbides, as shown in Fig. 5a and b. Compared to that in $\mathrm{N}$ and $\mathrm{T}$ specimens, the number of $M_{23} \mathrm{C}_{6}$-type carbides in specimens aged for $500 \mathrm{~h}$ increases significantly. In addition, the size of $M_{23} \mathrm{C}_{6}$-type carbides changes little in this stage, as presented in Fig. 7. Therefore, the strength of low-carbon RAFM steel after aging for $500 \mathrm{~h}$ is increased slightly. The second stage would start with the extension of aging exposure time, in which the main characteristic is the increase in the precipitate size. The coarsening of $M_{23} \mathrm{C}_{6}$ type carbides takes place when the specimen is aged for 1000 h, as shown in Fig. 5c, which leads to the localized loss of precipitation hardening and the loss of pinning effect on grain and lath boundaries, resulting in the decrease in strength. $\mathrm{Fe}_{2} \mathrm{~W}$ Laves phase precipitates on the grain boundaries and martensitic lath boundaries when the aging time reaches 3000 h, as shown in Figs. 4d and Fig. 5d. However, no Laves phase appears in the low-carbon RAFM steels after aging for 500 and $1000 \mathrm{~h}$ at $600{ }^{\circ} \mathrm{C}$. Laves phase precipitates at prior austenite grain boundaries and martensite lath boundaries, which are coherent with some grains but grow into adjacent lath grains with incoherent [36, 37]. $\mathrm{Fe}_{2} \mathrm{~W}$ Laves phase could act as barriers to dislocation and martensite lath movement, providing the precipitation strengthening for grain boundaries and lath boundaries, which leads to the increase in tensile and yield strengths of specimen aged for $3000 \mathrm{~h}$ [38]. It should be noted that the tensile and yield strength would decrease if the aging time is further prolonged. Since the growth of Laves phase is fast, the coarsening of Laves phase would dissolve $\mathrm{W}$ atoms near grain boundaries and lath boundaries, which could weaken the solid solution strengthening [39]. In addition, the coarsening of Laves phase directly swallows many adjacent $M_{23} \mathrm{C}_{6}$-type carbides on the boundaries of grain and martensite lath [40]. The stability of microstructure would be decreased obviously since no enough $M_{23} \mathrm{C}_{6}$-type carbides could pin on the grain boundaries and lath boundaries, which is harmful to the high-temperature mechanical properties of RAFM steels.

\section{Conclusions}

In this study, the microstructure evolution and mechanical property changes of low-carbon RAFM steel after $\mathrm{N}$ and $\mathrm{T}$ and isothermal aging heat treatments have been investigated. Based on above discussion the following conclusions are drawn:

1. There is no significant difference in the prior austenite grain size between the $\mathrm{N}$ and $\mathrm{T}$ and aged low-carbon RAFM steels. The tempered martensitic structure is relatively stable during aging.

2. In the initial thermal aging stage, the number of $M_{23} \mathrm{C}_{6}$ type carbides increases, resulting in the slight increase in the tensile strength for low-carbon RAFM steel after being aged for $500 \mathrm{~h}$. With aging time increasing, the growth of $M_{23} \mathrm{C}_{6}$-type carbides is significant, while $M X$ type precipitate exhibits a higher thermal stability.

3. After being aged at $600{ }^{\circ} \mathrm{C}$ for $3000 \mathrm{~h}, \mathrm{Fe}_{2} \mathrm{~W}$ Laves phase precipitates adjacent to $M_{23} \mathrm{C}_{6}$-type carbides along grain boundaries and martensitic lath boundaries. Lower carbon content can retard the precipitation of $\mathrm{Fe}_{2} \mathrm{~W}$ Laves phase compared to the RAFM steel containing higher carbon. $\mathrm{Fe}_{2} \mathrm{~W}$ Laves phase could provide the precipitation strengthening, which leads to the increase in tensile and yield strength of low-carbon RAFM steel aged for $3000 \mathrm{~h}$.

Acknowledgements The work was financially supported by the National Natural Science Foundation of China (Nos. U1660201, 51474156 and 51501126) and the National Magnetic Confinement Fusion Energy Research Project (No. 2015GB119001).

\section{References}

[1] J. Knaster, A. Moeslang, T. Muroga, Nat. Phys. 12, 426 (2016)

[2] S. Zinkle, A. Moeslang, T. Muroga, H. Tanigawa, Nucl. Fusion 53, 1 (2013)

[3] M. Gilbert, R. Forrest, Fusion Eng. Des. 81, 1511 (2006)

[4] J. Chen, Y. Liu, C. Liu, X. Zhou, H. Li, J. Mater. Res. 32, 1376 (2017)

[5] J. Chen, C. Liu, Y. Liu, B. Yan, H. Li, J. Nucl. Mater. 479, 295 (2016)

[6] J. Chen, Y. Liu, C. Liu, B. Yan, H. Li, J. Iron Steel Res. Int. 24, 705 (2017)

[7] Z. Xia, C. Zhang, Z. Yang, Mater. Sci. Eng. A 528, 6764 (2011) 
[8] Z. Xia, C. Zhang, N. Fan, Y. Zhao, F. Xue, S. Liu, Mater. Sci. Eng. A 545, 91 (2012)

[9] R. Klueh, D. Alexander, M. Rieth, J. Nucl. Mater. 273, 146 (1999)

[10] Q. Huang, N. Baluc, Y. Dai, S. Jitsukawa, A. Kimura, J. Konys, R. Kurtz, R. Lindau, T. Muroga, G. Odette, B. Raj, R. Stoller, L. Tan, H. Tanigawa, A. Tavassoli, T. Yamamoto, F. Wan, Y. Wu, J. Nucl. Mater. 442, S2 (2013)

[11] C. Mao, C. Liu, L. Yu, H. Li, Y. Liu, Mater. Sci. Eng. A 725, 283 (2018)

[12] C. Zhang, L. Cui, Y. Liu, C. Liu, H. Li, J. Mater. Sci. Technol. 34, 756 (2018)

[13] W. Liu, C. Zhang, Z. Yang, Z. Xia, Mater. Sci. Eng. A 583, 61 (2013)

[14] W. Liu, C. Zhang, Z. Xia, Z. Yang, J. Nucl. Mater. 455, 402 (2014)

[15] R. Lindau, A. Moslang, M. Rieth, M. Klimiankou, E. MaternaMorris, A. Alamo, A. Tavassoli, C. Cayron, A. Lancha, P. Fernandez, N. Baluc, R. Schaublin, E. Diegele, G. Filacchioni, J. Rensman, B. Schaaf, E. Lucon, W. Dietz, Fusion Eng. Des. 75, 989 (2005)

[16] Q. Lu, S. Zwaag, W. Xu, J. Mater. Sci. Technol. 33, 1577 (2017)

[17] G. Krauss, ISIJ Int. 35, 349 (1995)

[18] S. Morito, J. Nishikawa, T. Maki, ISIJ Int. 43, 1475 (2003)

[19] M. Taneike, F. Abe, K. Sawada, Nature 424, 294 (2003)

[20] M. Taneike, K. Sawada, F. Abe, Metall. Mater. Trans. A 35, 1255 (2004)

[21] X. Zhou, C. Liu, L. Yu, Y. Liu, H. Li, J. Mater. Sci. Technol. 31, $235(2015)$

[22] Z. Xia, C. Wang, Y. Zhao, G. Zhang, L. Zhang, X. Meng, Acta Metall. Sin. (Engl. Lett.) 28, 1238 (2015)

[23] X. Zhou, Y. Shen, Z. Xu, Acta Metall. Sin. (Engl. Lett.) 28, 48 (2015)
[24] X. Xiao, G. Liu, B. Hu, J. Wang, W. Ma, J. Mater. Sci. Technol. 31, 311 (2015)

[25] Y. Zhou, Y. Li, Y. Liu, Q. Guo, C. Liu, L. Yu, C. Li, H. Li, J. Mater. Res. 30, 3642 (2015)

[26] J. Chen, Y. Liu, Y. Xiao, Y. Liu, C. Liu, H. Li, Acta Metall. Sin. (Engl. Lett.) 31, 706 (2018)

[27] Z. Zhang, Z.F. Hu, H.Y. Tu, S. Schmauder, G.X. Wu, Mater. Sci. Eng. A 618, 74 (2017)

[28] Z. Xia, C. Zhang, H. Lan, Z. Yang, J. Mater. Sci. 46, 3151 (2011)

[29] A. Orlova, J. Bursik, K. Kucharova, V. Sklenicka, Mater. Sci. Eng. A 245, 39 (1998)

[30] R. Klueh, J. Nucl. Mater. 378, 159 (2008)

[31] H. Cui, F. Sun, K. Chen, L. Zhang, R. Wan, A. Shan, J. Wu, Mater. Sci. Eng. A 527, 7505 (2010)

[32] X. Guo, Y. Ni, J. Gong, L. Geng, J. Tang, Y. Jiang, X. Jia, X. Yang, Acta Metall. Sin. (Engl. Lett.) 30, 829 (2017)

[33] Z. Wang, T. Liang, W. Xing, A. Du, M. Gao, Y. Ma, K. Liu, Acta Metall. Sin. (Engl. Lett.) 31, 281 (2018)

[34] X. Hu, L. Huang, W. Yan, W. Wang, W. Sha, Y. Shan, K. Yang, Mater. Sci. Eng. A 586, 253 (2013)

[35] O. Prat, J. Garcia, D. Rojas, G. Sauthoff, G. Inden, Intermetallics 32, 362 (2013)

[36] X. Zhou, Y. Liu, C. Liu, L. Yu, H. Li, Mater. Res. Innov. 19, S193 (2015)

[37] Q. Li, Metall. Mater. Trans. A 37, 89 (2006)

[38] J. Hald, Steel Res. 67, 369 (1996)

[39] Z. Xia, C. Wang, C. Lei, Y. Lai, Y. Zhao, L. Zhang, J. Iron Steel Res. Int. 23, 685 (2016)

[40] Y. Xu, Y. Nie, M. Wang, W. Li, X. Jin, Acta Mater. 131, 110 (2017) 